\title{
Fresh Agri-Food Supply Chain Retailers and Suppliers Price Game
}

\author{
Qian Tong ${ }^{1, a}$ Xiao Xi Tong ${ }^{2, b}$ and Yuan Yuan $\mathrm{Li}^{3, \mathrm{c}}$ \\ ${ }^{2}$ Kunming University of Science and Technology, City College ,Kunming 650000. \\ ${ }^{3}$ Kunming Metallurgy commercial college, Kunming 650000 \\ ${ }^{3}$ Kunming University of Science and Technology, Kunming 650000 \\ a1104688315@qq.com, b47123607@qq.com,cyyuanli@qq.com
}

Keywords: Supply chain; Fresh agri-foods; Game; Retailers; Suppliers

\begin{abstract}
In the supply chain of fresh agricultural foods and food safety, participants for each activity are making their efforts to obtain the maximize benefits, and every interests owners are playing the maximizing benefit Game. As the main parts in the supply chain, suppliers provide their Optimal order quantity and the corresponding punitive cost strategy basing on the least cost target. On the contrary, retailers as the following parts, whose ordering costs and inventory costs are fully controlled by suppliers. Suppliers put the extra supply capacity to get maximum benefit as response, whereas retailers have to obey the decisions made by the suppliers. This paper analyzes two cases in the supply chain: establishing game model with completely independent decision-making and with information sharing. Furthermore, it also take full advantage of Game model to obtain the model between suppliers and retailers in Supply Chain. Finally the paper discusses that when suppliers and retailers achieve the optimal Game effect at the case of cooperation, whether both benefits keep the direct relationship with their investment.
\end{abstract}

\section{Introduction}

A complete supply chain activities includes logistics, capital flow, information flow and they are combined into an organic entirety. Only when the overall system coordinate well, can each activity achieve an optimal effect. Fresh agricultural products belong to perishable foods, so costs in inventory and transportation are highest throughout the supply chain. Therefore in the supply chain activities people can take a coordinated mechanism to coordinate specific inventory of the supply chain by using the supplement period. So far, many scholars use the supply chain to do some research, such as Kirstin Zimmer studied the supply chain coordination in uncertain delivery. Kirstin Zimmer analyzed the suppliers' decision-making behavior under the situation that suppliers and suppliers are completely independent when making decisions in the worst case, also analyzed the joint optimizing decision-making behavior when supply chain are looked as a fully vertically integrated companies under the situation that suppliers and suppliers are completely information sharing in the best case.

\section{Modeling research questions}

In the supply chain of fresh agricultural products, the relationship between suppliers and retailers is direct trade. Because there are some losses of fresh agricultural products in stock and shipping 
process, it is necessary in the supply chain to add an additional variable $U$, retailers final product demand $D$, the cost $\pi 1$ required to spend each year for retailers, the average total cost $\pi 2$ which covers suppliers' annually order costs and transportation costs. Q is the quantity retailers shares in the market, $\mathrm{C}$ is the unit cost of goods, $\mathrm{P}$ is the price of unit goods, $\mathrm{K} 1$ are unit inventory carrying costs for the retailer's, K2 are stock keeping unit costs for suppliers, $\mathrm{C} 1$ is the cost per order for retailers, $\mathrm{V}$ is demand rate of market for commodities, $\mathrm{T}$ is the retailer's out of stock time or suppliers' delivery time, S1 is the highest inventory of retailers, S2 is retailers' shortage cost, A are the transportation costs from suppliers to the retailers, $h$ is unit holder cost of the retailer's, $n$ is the order times every year, taking the number of regular orders, $\mathrm{m}$ is common replenishment for suppliers, $\mathrm{d}$ is compensation value for suppliers, $\mathrm{X}$ is the external needs retailer faced with during each replenishment order period. Demanding obeys to the normal distribution function of $N(\mu$, $\left.\sigma^{2}\right), \mathrm{E}$ is the random demand order point that people faced with each time The cost function of suppliers and retailers are discussed below .

It costs $\pi 1$ every time for retailers to deal with orders:

$$
\pi_{1}=C_{1} / T+\frac{1}{2} K_{1} V T+U(1+d) p
$$

The cost that suppliers need to pay for during dealing with transaction with retailers is $\pi 2$

$$
\pi_{2}=C_{2} / T+\frac{1}{2} K_{2} T V+U(1+d) p
$$

The annual cost of goods for retailers:

$$
Q=\sum_{i=1}^{n} P\left(S_{i}-\int_{0}^{S_{n}}\left(S_{i}-X_{i-1}\right) f\left(X_{i-1}\right) d x_{i-1}\right)
$$

Annual inventory costs of retailers:

$$
W=\sum_{i=1}^{n} P T\left(S_{i}-X_{i}\right) h \int_{0}^{s_{i}}\left(S_{i}-X_{i}\right) f\left(x_{i}\right) d x_{i}
$$

Annual shortage cost of retailers:

$$
E=\sum_{i=1}^{n} S T \int_{0}^{\infty}\left(X_{i}-S_{i}\right) f\left(x_{i}\right) d x_{i}
$$

The summery of each cost of retailer is his total cost, so total cost function is: order cost + freight costs + inventory cost + shortage cost

$$
\begin{aligned}
& \pi_{r}(T, S)=\pi_{1}+Q+W+E \\
& =n\left(C_{1} / T+\frac{1}{2} K_{1} V T\right)+\sum_{i=1}^{n} P\left(S_{i}-\int_{0}^{S_{i}}\left(S_{i}-X_{i-1}\right) f\left(X_{i-1}\right) d x_{i-1}\right)+ \\
& \sum_{i=1}^{n} S T \int_{0}^{i}\left(X_{i}-S_{i}\right) f\left(x_{i}\right) d x_{i}+2 U(1+d) p+\sum_{i=1}^{n} P T\left(S_{i}-X_{i}\right) h \int_{0}^{s_{i}}\left(S_{i}-X_{i}\right) f\left(x_{i}\right) d x_{i} \\
& =C_{1}+\frac{1}{2} K_{1} V+2 U(1+d) p+\frac{P}{T}\left[S_{1}-E\left(S_{1}-X\right)\right]+\frac{1}{2} P h\left[S_{1}+E\left(S_{1}\right)^{T}\right)+\frac{S}{T} E\left(X-S_{1}\right)
\end{aligned}
$$

Throughout the course of the activity, cost that suppliers have to spend includes transportation costs, i.e. the cost from suppliers to retailers, and the cost to deal with orders. 


$$
\pi_{s}(T, S)=\sum_{i=1}^{n}\left(C_{i}+A_{i}\right) n
$$

The analysis of cost function and data modeling under different game strategies In his research, Kirstin Zimmer analyzed suppliers and retailers through two cases, namely under the best situation and the worst one. At the worst situation in analysis, suppliers and retailers separately used their own information, without information being shared and independent optimized their own objective functions in the cost function..

Game where the retailer is main part . In order to get the maximize profits, retailers determine the optimal delivery time $\mathrm{T}$ and optimal inventory S1 by minimizing their total costs. In the course of the game, retailers are at the absolute advantage position, and the results of one are better than another. Get the first derivative of inventory function (6) in the game's dominant and compliance strategy as below:

$$
\frac{d \pi_{r}(T, R)}{d S}=\frac{P}{T}\left[1-F_{T}(S)\right]+\frac{1}{2} P h\left[1+F_{T}(S)\right]
$$

When the first derivative of the optimal inventory is zero, we can get the extreme point. By using

$$
\begin{gathered}
\frac{d \pi_{r}(T, R)}{d S}=0 \\
\text { (8) }, \text { we can get } \\
F(S)=F\left(\frac{S-\mu}{\sqrt{\sigma}}\right)=\frac{K-P h T / 2-P}{K+P h T / 2-P}
\end{gathered}
$$

So, when the retailer's ordering replenishment cycle $\mathrm{T}$ is given, we can calculate the $\mathrm{S}$ through the equation (9). In the game's dominant and compliance strategy discussed above, the dominant one of the strategy is the retailer who raised its optimal delivery and optimal inventory, at the same time, the compliance one are suppliers who determine the optimal inventory policies according to the dominant one's strategy. According to the common compensation time $\mathrm{T}$ provided by suppliers and retailers and the minimizing total cost $\pi$, we can have the compensation value $d$ provided by the supplier to minimize the total cost of the supplier function.

$\min \pi_{s}=\frac{C_{i}}{T}+\sum_{i=1}^{n}\left(d+\frac{A_{i}}{T}\right)+\sum_{i=1}^{n}\left(\frac{C_{i}+A_{i}}{T}\right)$

Stackelberg model benefitting both manufacturers and retailers. When solving the optimal inventory, the total cost of the supply chain spends is $\pi_{c}(T, L)$, which is the summary of the cost that when suppliers deal with each time retailers' ordering and the cost that each time suppliers spends to deal with the retailers' ordering. Adding formula (1) to the formula (2), we get the ordering cost of the suppliers.

$\pi_{c}(T, L)=C_{1} / T+\frac{1}{2} K_{1} V T+U(1+d) p+C_{2} / T+\frac{1}{2} K_{2} T V+U(1+d) p$

To further simplify formulate (11) we can have a handy formulation about (T, L)

$\pi_{C}=\frac{1}{T}\left[C_{1}+C_{2}+\frac{1}{2} E\left(K_{1}+K_{2}\right)(T-L)^{2}+\frac{1}{2} S E L^{2}\right]+2 U(1+d) P$

In order to get the least total cost, we should firstly get the derivative of $(T, L)$ respectively in supply chain model, and then we can get the min value in the model. 


$$
\begin{gathered}
\frac{\partial \pi_{c}}{\partial L}=\left(K_{1}+K_{2}\right)\left(\frac{L}{T}-1\right) V+E V \frac{L}{T} \\
\frac{\partial \pi_{c}}{\partial T}=\frac{1}{2} E\left(K_{1}+V\right)-\frac{1}{2} V \frac{L^{2}}{T^{2}}\left(S+K_{1}+K_{2}\right)-\frac{1}{T^{2}}\left(C_{1}+C_{2}\right)
\end{gathered}
$$

When each derivative of (T, L) is calculated, set them as zero, that is formulation (13) and formulation (14) are both zero.

$$
\begin{aligned}
& \mathrm{L}=\sqrt{\frac{2\left(C_{1}+C_{2}\right)\left(K_{1}+K_{2}+S\right)}{S V\left(K_{1}+K_{2}\right)}} \\
& \mathrm{T}=\sqrt{\frac{2\left(C_{1}+C_{2}\right)\left(K_{1}+K_{2}\right)}{S V\left(S+K_{1}+K_{2}\right)}}
\end{aligned}
$$

Bring the results of formula (15) and (16) into the equation (12) and we can get the minimum cost

$$
\pi_{c}=\sqrt{\frac{2 S V\left(C_{1}+C_{2}\right)\left(K_{1}+K_{2}\right)}{S+K_{1}+K_{2}}}+2 U(1+d) P
$$

\section{Summary}

In the paper, by establishing the cost equation of supply chain and the cost equation of dealing with orders every year and cost in transportation and by comparing with different competitive strategies in the game, the average cost function of suppliers' and retailers' can be analyzed by data.

\section{References}

[1] Huang Xiaoyuan. Supply chain model and optimization research and development. Information and Control. (2013)

[2] Kristin Z. Supply chain coordinating with uncertain just-in-time delivery. Internal Journal of production Economics. (2012)

[3] Chopra S. Lovejoy W. Yano C. Five decades of operations management and the prospects ahead [J].Management Science, 2004,50(1):pp.8-14.

[4] Clements M D, Lazo R M, Martin S K. Relationship connectors in NZ fresh produce supply chains [J]. British Food Journal, 2008, 110(4/5): 346-360.

[5] Ning Y, Rong L, Liu .1. Inventory models for fresh agriculture products with time-varying deterioration rate[J]. Industrial Engineering \& Management Systems, 2013(3): 23 -20.

[6] Nestle, $M$.Food Politics: How the Food Industry Influences Nutrition and Health [M] .University of Cali-forma Press, 2009.

[7] Peter Raspor .Total food chain safety: how good practices can contribute[J] .Trends in Food Science \& Technology .Volume 19, Issue 8, August 2008: 405-412

[8] Opara, L. U. Traceability in agriculture and food supply chain: A review of basic concepts, technological implications, and future prospects [J].Journal of Food, Agriculture and Environment,

[9] Tah, J. H . M., Carr, V. Towards a framework for project risk knowledge management in the construction supply chain [J] Advances in Engineering Software, 2010, 32(10):835-816. 
[10] Rolf Meyer. Comparison of scenarios on futures of European food chains [J] .Trends in Food Science \& Technology, Volume18, Issue 11, November 2009: 540-545 